\title{
In-Law Preferences: Do Fathers and Mothers Agree on What They Want in a Daughter-in-Law and in a Son-in-Law?
}

\author{
Menelaos Apostolou ${ }^{1}$
}

Published online: 11 April 2016

(C) Springer International Publishing 2016

\begin{abstract}
Parents across societies and across time have been exercising considerable influence over their children's mate choices. Parents desire specific traits in a prospective spouse for their children; however, the contribution of those traits to the parents' fitness is contingent upon whether they are found in a daughter- or a son-in-law. Furthermore, certain traits can potentially make a different fitness contribution to mothers and fathers. On this basis, by using a comprehensive instrument of in-law preferences and a within-family design, the present study tests the hypotheses that (a) in-law preferences are contingent upon the sex of the in-law and (b) in-law preferences are contingent upon the sex of the parent. Evidence from a sample of 541 families finds support for both hypotheses.
\end{abstract}

Keywords In-law preferences · Sex difference in in-law preferences $\cdot$ Parental choice $\cdot$ Mate choice

\section{Introduction}

Across time and societies, parents exercise considerable influence over their children's mating decisions (Broude and Green 1983; Stephens 1963). In contemporary and in ancestral preindustrial societies, the prevalent mode of long-term mating is arranged marriage, where parents choose spouses for their children (Apostolou 2010b). In post-industrial societies, parents cannot control directly their children and they do so

Menelaos Apostolou

m.apostolou@gmail.com

1 University of Nicosia, 46 Makedonitissas Ave., 1700 Nicosia, Cyprus indirectly through using a wide range of manipulation tactics (Apostolou and Papageorgi 2014). The influence that parents exercise on their children raises the questions of (a) whether mothers and fathers are in agreement with each other on what they prefer in a spouse for their children and (b) whether what parents prefer is contingent upon the sex of their prospective in-laws. The present research aims to address both questions.

\section{Parental Control Over Mating and the Evolution of In-Law Preference}

Before examining the contingencies in parental control over mating, we need to examine why parents are motivated to control their children's mating decisions in the first place. The primary reason is that parents and children have diverging interests over mating, which means that children's mate choices are not always to their parents' best interest, motivating parents to place their children's mate choices under their own control (Apostolou 2014c, 2015b).

In detail, parents and children are genetically related, with the latter getting all their genetic material from the former. Nevertheless, although children receive all their genes from their parents, not all of the parents' genes are inside their children. That is to say, parents and children are genetically related, but not genetically identical. This means that their genetic interests do not completely overlap and in certain domains diverge. One of these domains is mate choice (Trivers 1974).

More specifically, due to the differences in genetic relatedness between parents and children, the traits of a prospective mate for the children will make different contributions to the fitness of each party. Such a trait is, for example, good genetic quality, which is more beneficial in a spouse than in an in-law. The reason is that the genetic relatedness between parents and 
children is 0.5 , whereas the genetic relatedness between parents and grandchildren is 0.25 . Therefore, the probability of a particular gene being passed on to the next generation by a spouse or by an in-law is 50 or $25 \%$, respectively. It follows that individuals reap more genetic benefits from a spouse than from an in-law of superior genetic quality, and, as a result, they are predisposed to prefer good genetic quality more in a spouse than in an in-law (Apostolou 2015a, b; Buunk et al. 2008). So far, research has identified that children value good looks (a proxy of genetic quality) more in a spouse than their parents in an in-law; similarly, parents value good family background and similarity in religious beliefs more in an inlaw than their children do in a spouse (Apostolou 2015b; Buunk et al. 2008; Perilloux et al. 2011).

The non-overlapping in-law and mate preferences lead to asymmetrical compromises for parents and children and an eventual conflict between the two (Apostolou 2011). In particular, mate choice involves various compromises as individuals are constrained by their own mate value and cannot get mates who score high in all traits (Li et al. 2002). Accordingly, in order to get a trait they desire more (e.g., exciting personality), children make compromises on traits they desire less (e.g., good family background). Such compromises are not optimal for parents, who value beauty less, but value good family background more than their children (Apostolou 2011).

Overall, children's mating decisions are not optimal for their parents, which motivate the latter to place the former's mate choices under their control. Evidence from anthropological and historical records and phylogenetic analysis indicates that parents were successful in doing so (Apostolou 2014c; Walker et al. 2011). In turn, effective control over mating exercises selection pressures on parents to evolve in-law preferences that enable them to choose sons- and daughters-in-law who maximize their own fitness rather than that of their children. These preferences are expected to be contingent upon the sex of the parent and the sex of the offspring.

\section{Daughters-in-Law vs. Sons-in-Law}

We can start by examining why in-law preferences are expected to be contingent on the sex of the in-law. The human species is sexually reproducing, with each sex having different specializations with respect to reproduction (Whyte 1978). For instance, women specialize in providing the protected environment for the fetus to develop, before it is able to function in a non-protective environment. Consequently, after a successful mating encounter, women have to remain longer than men out of the mating market, which turns them into the scarce reproductive resource over which men compete against each other for access (Emlen and Oring 1977; Trivers 1972). One way men compete against each other is through fighting and monopolizing access to women (Puts 2010). In turn, strong selection pressures are exercised on men to evolve those adaptations, which will enable them to effectively fight other men or rivals. As a consequence of these selection pressures, men are, on average, physically stronger than women, they have a bigger body size, and they are more aggressive (Puts 2010).

Differential selection forces exercised on men and women have led them to evolve different traits, which in turn makes them more able and fit to fill different social niches and assume different roles in the subsistence and survival effort of the societal unit. For example, in foraging societies hunting and war efforts, which require strength and aggression, are men's domains, while plant gathering, which does not require scoring high in these specific traits, is women's domain (Lee and Devore 1968).

The division of labor by sex means that for parents, the fitness value of a prospective in-law's traits is contingent upon the sex of the in-law. For instance, physical strength has a higher fitness value in a prospective son-in-law than in a prospective daughter-in-law. The reason is that a physically strong son-in-law will be an effective warrior and hunter and, thus, provide parents and their family with food and protection; however, a physically strong daughter-in-law will not be equally beneficial, as she will not engage in protection and hunting efforts.

Overall, differential selection pressures and differential adaptive problems that need to be solved by men and women lead each sex to be endowed with different adaptations, which lead to a division of labor; this indicates that the fitness benefits of specific traits in prospective in-laws are contingent upon their sex. Consequently, differential selection pressures are exercised on in-law preferences, making them to diverge over traits which have differential fitness potential in a daughter-in-law and in a son-in-law (Apostolou 2007). Simply put, parents are expected to alter their preferences in specific domains, depending on the sex of their prospective inlaw. Note that this reasoning does not only apply to in-law preferences but also apply to mate preferences, which are contingent on the sex of the prospective mate. Certain traits, such as beauty, are valued differently in a female and in a male partner (Buss 2003).

Several studies find evidence consistent with this prediction. More specifically, studies in post-industrial societies, which asked participants to rate the desirability of several traits, found that parents ascribe more value to traits associated with good resource provision potential, such as "good financial prospects" and "industriousness" in a son- than in a daughter-in-law; similarly, they ascribe more value to good looks and good housekeeping abilities to a daughter- than a son-in-law (Apostolou 2007; Perilloux et al. 2011). Similar results were obtained by a study exploring in-law preferences in a sample of 67 pre-industrial societies, which also 
found that chastity is preferred more in a daughter- than a son-in-law (Apostolou 2010a).

One limitation of the studies above is that they examined in-law preferences using instruments originally designed to measure mate preferences, so they may not be able to capture the full range of traits that parents desire. One exception was Apostolou (2014a), which examined in-law preferences with an instrument specifically designed for this purpose. Nevertheless, the factor structure derived using that instrument was based on a relative small sample $(N=621)$. To account for this limitation, a recent study employed a large sample of parents $(N=1717)$ and derived a similar, but different instrument, which better reflects the structure of in-law preferences (Apostolou 2015a). Accordingly, the present study aims to investigate the contingencies of in-law preferences in this preferences structure.

\section{Mothers vs. Fathers}

It had been argued originally that the different traits in a prospective daughter- and son-in-law provide similar fitness benefits to both fathers and mothers, so the two are expected to share the same preferences when it comes to in-law choice (Apostolou 2007). Nevertheless, subsequent theorizing has indicated that this is not the case (Apostolou 2014b, 2015b).

To begin with, due to menopause, women conclude their reproductive careers at an earlier age than men. As a consequence, the residual reproductive value (i.e., the contribution to the population through future reproduction) is less for older women - to the point of being zero if they have passed the age of menopause - than it is for men of the same age (Apostolou 2014b). Thus, a mating deal involving their children can be more beneficial for fathers, as it can provide them with resources, which can be allocated to future reproduction.

In addition, men have a higher reproductive variance than women, as they are not constrained by their biology in the number of children they can father. Men's reproductive success is positively related to the resources they control (Buss 2003). Men are able to deploy resources in such a way that enables them to practice polygyny and/or to attract multiple casual mates (Goode 1982). On the other hand, as women are constrained by their biology, polyandrous marriage, and having multiple casual mates, these do not increase their reproductive success. In effect, a mating deal for their children, which provides parents with resources, can potentially be more beneficial to a father than to a mother, as the father can use these resources to directly increase his future reproductive success. To put this in another way, the resources from a mating deal involving their children have the potential to increase the father's direct reproductive success to a considerably greater degree than the mother's direct reproductive success (Apostolou 2014b).
Women give birth to their children, and so they do not face parental uncertainty. This is not the case for men, who cannot be certain that they have fathered the children their partners gave birth to. Consequently, if children are harmed by their mates, the fitness cost is potentially higher for mothers, as the cost for fathers needs to be discounted by the possibility that these children are not actually their own (Apostolou 2014b). Furthermore, because women conclude their reproductive career earlier than men, the fitness cost from the loss of a child due to an abusive mate will be higher for mothers, as fathers are more likely to have the capacity to have additional offspring to cover that loss. On this basis, it is predicted that mothers would ascribe more importance than fathers to traits such as kindness and caring, which better predict the safety of their children and ensure their welfare. In sum, fathers are expected to have stronger preferences for traits that could directly affect their fitness, whereas mothers are expected to have stronger preferences for traits that could indirectly affect their fitness.

Overall, it is expected that there will be different traits in a prospective in-law benefiting one parent more than the other and that these trait preferences will diverge depending on the sex of the parent. For the areas where there is no differential fitness benefit, the preferences will not diverge. One nominated area where preferences are expected to diverge is resources; it is predicted that fathers will place more emphasis than mothers on this trait, as historically this would have enabled them to increase their fitness more. Another area of divergence is traits that predict the welfare and safety of children. It is predicted that these traits will be preferred more by mothers than fathers.

The evidence is currently inconclusive. In particular, in one of the first studies of in-law preferences involving a sample of 297 British parents, no significant differences in preferences between fathers and mothers were found (Apostolou 2007). However, the sample involved only 72 men, meaning the study might not have been powerful enough to detect any sex differences. In a more comprehensive research of in-law preferences, which involved participants assessing 88 traits, classified in 11 dimensions, it was found that mothers considered "pleasant and cooperative" and "exciting personality" more important in a son-in-law than fathers did. They also considered "family-oriented," "good economic prospects," "emotionally stable and mature," and "kind and understanding" to be more important in both a son- and a daughter-in-law than fathers did (Apostolou 2014a).

One study in the USA compared the rankings 117 fathers and 121 mothers gave for 13 traits in a prospective in-law (Perilloux et al. 2011). They found only one significant difference, where mothers ranked the "wants children" higher than fathers. They also found a trend for fathers to rank "creative" higher than mothers. In a different line of research, Dubbs and Buunk (2010) found that daughters perceive a low-quality 
partner (e.g., traits indicating poor parental investment) to be more unacceptable to their mother than their father, while having a partner with traits indicating low social status as more unacceptable to their father than their mother. This research does not investigate preference differences between fathers and mothers, but it hints that such differences may actually exist.

As discussed previously, most of the existing research in this area is based upon instruments predominantly measuring mate preferences, which suggests that important areas of disagreement between parents may have been missed. Accordingly, this present research aims to investigate agreement and disagreement between parents using a newly developed and comprehensive instrument of in-law preferences (i.e., Apostolou 2015b). In addition, previous research efforts have compared the preferences of men and women who were not related to each other. However, in this research we are mainly interested in examining whether there is intrafamily conflict; that is to say, whether fathers and mothers in the same family agree or disagree over these preferences. It may be, for instance, that two individuals have different preferences, but when they have children together their preferences converge, so in effect, there is no disagreement between the two. The opposite can also occur, but the current literature has not examined whether this is the case.

Overall, fitness differentials can lead to divergence in preferences. It has been argued that because certain traits provide different fitness benefits in a son- and in a daughter-in-law, as well as different benefits for fathers and mothers, in-law preferences will be contingent upon the sex of the in-law and the sex of the parent. This study aims to examine these hypotheses by comparing the preferences of parents in the same family, using an instrument which more accurately measures in-law preferences.

\section{Method}

For the purposes of this research, we employed a dataset from a study which was designed to examine divergence between in-law and mate preferences (i.e., Apostolou 2015b). This dataset is appropriate for our purposes because it involves within-family comparisons and a relatively large number of participants. More specifically, the dataset included 541 Greek-Cypriot families, consisting of 979 parents (512 women, 467 men). The mean age of mothers was 47 years $(\mathrm{SD}=6.8$, range $=45)$, and the mean age of fathers was 50.7 years $(\mathrm{SD}=7.5$, range $=37)$. This was a family research, in the sense that all fathers and mothers in the sample had children together.

Families were visited at their homes by the research assistants who administered the survey. Parents were asked to rate the desirability of 88 traits in a prospective spouse for their daughters and sons using a four-point Likert scale (0, unimportant; 1, somehow important; 2, important; 3 , indispensable). The 88 traits were selected on the basis of earlier studies which aimed to develop a comprehensive instrument of the traits that individuals desire in a prospective spouse and in-law (Apostolou 2015b).

\section{Results}

Previous research applied principal components analysis on a large sample of participants has revealed that the 88 desirable traits cluster in 10 primary domains of interest (Apostolou 2015b). Reliability analysis indicated a high internal consistency for the scales in each domain, with Cronbach's $\alpha$ ranging from 0.76 to 0.91 , with a mean of 0.82 . Accordingly, this study will examine contingencies in each of these domains. More specifically, in order to examine whether in-law preferences are contingent on the sex of the parent and the sex of the in-law, doubly multivariate analysis (which is statistically equivalent to repeated measures MANOVA) was conducted for each of the 10 domains. In each case, the participants' scores for each traits belonging to each domain entered as the dependent variables and the sex of the parent (mother/ father) and the sex of the in-law (daughter-in-law/son-inlaw) entered as the independent variables.

Furthermore, there are 13 traits which do not load in any of the 10 factors. To examine our hypotheses for these traits, we applied as series of repeated measures of two-way ANOVAs, where the participants' scores for each trait entered as the dependent variables and the sex of the parent and the sex of the in-law entered as the independent variables. The sex of the parent is treated as a within-participants factor because the research employs a within-family design, and fathers' and mothers' scores are not independent. The results are presented in Tables 1 and 2.

With respect to the preference domains, 10 different statistical tests, one for each domain, were performed, which is likely to inflate the alpha level. Accordingly, Bonferroni correction can be applied to reduce alpha to $0.005(0.05 / 10)$. With respect to the comparisons of individual traits (Table 2), 13 tests were performed, so the alpha could be reduced to 0.003 $(0.05 / 13=0.003)$. We base our results on the unadjusted levels, but the reader may choose not to consider significant any differences which are above the 0.005 and the 0.003 levels, respectively.

\section{Daughters-in-Law vs. Sons-in-Law}

From Table 1, we can see that the "good looks" and the "good cook, housekeeper" are significantly more important in a daughter-in-law than in a son-in-law. The "family-oriented" is also preferred more in a daughter-in-law than in a son-in- 
Table 1 Sex differences in the 10 in-law preference domains

\begin{tabular}{|c|c|c|c|c|c|c|c|c|}
\hline Preferences & $\begin{array}{l}\text { Mother } \\
\text { Means (SD) }\end{array}$ & $\begin{array}{l}\text { Father } \\
\text { Means (SD) }\end{array}$ & $p$ values & $\eta_{p}^{2}$ & $\begin{array}{l}\text { Son-in-law } \\
\text { Means (SD) }\end{array}$ & $\begin{array}{l}\text { Daughter-in-law } \\
\text { Means (SD) }\end{array}$ & $p$ values & $\eta_{p}{ }^{2}$ \\
\hline Kind, understanding, and cooperative & $2.15(0.57)$ & $2.09(0.55)$ & n.s. & n.s. & $2.09(0.56)$ & $2.13(0.56)$ & n.s. & n.s. \\
\hline Good looks & $1.39(0.54)$ & $1.42(0.52)$ & .006 & 0.060 & $1.37(0.48)$ & $1.44(0.52)$ & $<.001$ & 0.137 \\
\hline Thin & $1.24(0.72)$ & $1.29(0.73)$ & n.s. & n.s. & $1.24(0.71)$ & $1.28(0.74)$ & n.s. & n.s. \\
\hline Nice body & $1.50(0.74)$ & $1.47(0.81)$ & n.s. & n.s. & $1.49(0.72)$ & $1.48(0.75)$ & n.s. & n.s. \\
\hline Good looking & $1.56(0.073)$ & $1.66(0.74)$ & .039 & 0.013 & $1.51(0.70)$ & $1.72(0.72)$ & $<.001$ & 0.063 \\
\hline Athletic & $1.37(0.70)$ & $1.46(0.79)$ & n.s. & n.s. & $1.44(0.76)$ & $1.39(0.80)$ & n.s. & n.s. \\
\hline Beautiful eyes & $1.21(0.75)$ & $1.10(0.73)$ & .016 & 0.018 & $1.10(0.73)$ & $1.20(0.71)$ & .043 & 0.013 \\
\hline Tall & $1.23(0.77)$ & $1.32(0.78)$ & .043 & 0.013 & $1.30(0.78)$ & $1.24(0.76)$ & n.s. & n.s. \\
\hline Charming & $1.62(0.71)$ & $1.63(0.72)$ & n.s. & n.s. & $1.50(0.71)$ & $1.73(0.72)$ & $<.001$ & 0.072 \\
\hline Spontaneous and selfless & $1.65(0.41)$ & $1.68(0.43)$ & .016 & 0.064 & $1.64(0.39)$ & $1.68(0.39)$ & n.s. & n.s. \\
\hline Selfless & $1.58(0.71)$ & $1.63(0.73)$ & n.s. & n.s. & n.s. & n.s. & n.s. & n.s. \\
\hline Spontaneous & $1.52(0.71)$ & $1.60(0.69)$ & n.s. & n.s. & n.s. & n.s. & n.s. & n.s. \\
\hline Sensitive & $1.76(0.68)$ & $1.70(0.72)$ & n.s. & n.s. & n.s. & n.s. & n.s. & n.s. \\
\hline Long-sighted & $1.62(0.72)$ & $1.61(0.76)$ & n.s. & n.s. & n.s. & n.s. & n.s. & n.s. \\
\hline Imaginative & $1.36(0.76)$ & $1.48(0.70)$ & .030 & 0.015 & n.s. & n.s. & n.s. & n.s. \\
\hline Extrovert & $1.43(0.65)$ & $1.53(0.64)$ & .032 & 0.015 & n.s. & n.s. & n.s. & n.s. \\
\hline Modest & $1.85(0.75)$ & $1.89(0.73)$ & n.s. & n.s. & n.s. & n.s. & n.s. & n.s. \\
\hline Strong personality & $1.81(0.70)$ & $1.80(0.69)$ & n.s. & n.s. & n.s. & n.s. & n.s. & n.s. \\
\hline Open-minded & $1.95(0.74)$ & $1.86(0.71)$ & .027 & 0.015 & n.s. & n.s. & n.s. & n.s. \\
\hline Good cook, housekeeper & $1.67(0.53)$ & $1.71(0.50)$ & n.s. & n.s. & $1.54(0.52)$ & $1.83(0.57)$ & $<.001$ & 0.145 \\
\hline Good cook & n.s. & n.s. & n.s. & n.s. & $1.29(0.79)$ & $1.63(0.75)$ & $<.001$ & 0.091 \\
\hline Good housekeeper & n.s. & n.s. & n.s. & n.s. & $1.47(0.72)$ & $1.77(0.71)$ & $<.001$ & 0.069 \\
\hline Tidy & n.s. & n.s. & n.s. & n.s. & $1.85(0.69)$ & $2.07(0.72)$ & $<.001$ & 0.071 \\
\hline Well-off family background & $1.33(0.59)$ & $1.47(0.63)$ & $<.001$ & 0.101 & $1.47(0.58)$ & $1.45(0.59)$ & n.s. & n.s. \\
\hline From a wealthy family & $1.03(0.77)$ & $1.34(0.80)$ & $<.001$ & 0.077 & n.s. & n.s. & n.s. & n.s. \\
\hline Wealthy & $1.21(0.81)$ & $1.43(0.79)$ & $<.001$ & 0.040 & n.s. & n.s. & n.s. & n.s. \\
\hline Good social status & $1.71(0.73)$ & $1.72(0.75)$ & n.s. & n.s. & n.s. & n.s. & n.s. & n.s. \\
\hline From a family of similar social status & $1.37(0.78)$ & $1.38(0.81)$ & n.s. & n.s. & n.s. & n.s. & n.s. & n.s. \\
\hline Similar religious and ethnic background & $1.81(0.51)$ & $1.76(0.60)$ & $<.001$ & 0.081 & $1.80(0.50)$ & $1.79(0.52)$ & n.s. & n.s. \\
\hline Same nationality & $2.01(0.78)$ & $1.83(0.81)$ & .001 & 0.033 & n.s. & n.s. & n.s. & n.s. \\
\hline Same religion & $2.013(0.82)$ & $2.05(0.76)$ & n.s. & n.s. & n.s. & n.s. & n.s. & n.s. \\
\hline Religious & $1.85(0.68)$ & $1.77(0.74)$ & n.s. & n.s. & n.s. & n.s. & n.s. & n.s. \\
\hline Similar political beliefs & $1.01(0.80)$ & $1.17(0.81)$ & .001 & 0.032 & n.s. & n.s. & n.s. & n.s. \\
\hline Good family background & $2(0.76)$ & $1.96(0.80)$ & n.s. & n.s. & n.s. & n.s. & n.s. & n.s. \\
\hline Reliable and tolerant & $2.05(0.48)$ & $2.05(0.49)$ & n.s. & n.s. & $2.07(0.54)$ & $2.03(0.53)$ & $<.001$ & 0.116 \\
\hline Tolerant & n.s. & n.s. & n.s. & n.s. & $1.96(0.79)$ & $1.91(0.76)$ & n.s. & n.s. \\
\hline Serious & n.s. & n.s. & n.s. & n.s. & $2.04(0.72)$ & $1.97(0.78)$ & n.s. & n.s. \\
\hline Calm & n.s. & n.s. & n.s. & n.s. & $1.97(0.74)$ & $2.06(0.70)$ & n.s. & n.s. \\
\hline Reliable & n.s. & n.s. & n.s. & n.s. & $2.17(0.70)$ & $2.16(0.72)$ & n.s. & n.s. \\
\hline Determined & n.s. & n.s. & n.s. & n.s. & $2.10(0.66)$ & $1.96(0.70)$ & .001 & 0.031 \\
\hline Respectful & n.s. & n.s. & n.s. & n.s. & $2.24(0.75)$ & $2.28(0.75)$ & n.s. & n.s. \\
\hline Ambitious & n.s. & n.s. & n.s. & n.s. & $1.68(0.73)$ & $1.65(0.69)$ & n.s. & n.s. \\
\hline Generous & n.s. & n.s. & n.s. & n.s. & $2.05(0.70)$ & $1.82(0.68)$ & $<.001$ & 0.066 \\
\hline Good communication & n.s. & n.s. & n.s. & n.s. & $2.15(0.72)$ & $2.08(0.68)$ & n.s. & n.s. \\
\hline Polite & n.s. & n.s. & n.s. & n.s. & $2.06(0.73)$ & $2.11(0.74)$ & n.s. & n.s. \\
\hline Family-oriented & $2.38(0.58)$ & $2.33(0.59)$ & n.s. & n.s. & $2.29(0.60)$ & $2.33(0.59)$ & $<.001$ & 0.135 \\
\hline Loves my daughter/son & n.s. & n.s. & n.s. & n.s. & $2.38(0.80)$ & $2.41(0.79)$ & n.s. & n.s. \\
\hline Loves children & n.s. & n.s. & n.s. & n.s. & $2.37(0.73)$ & $2.40(0.76)$ & n.s. & n.s. \\
\hline
\end{tabular}


Table 1 (continued)

\begin{tabular}{|c|c|c|c|c|c|c|c|c|}
\hline Preferences & $\begin{array}{l}\text { Mother } \\
\text { Means (SD) }\end{array}$ & $\begin{array}{l}\text { Father } \\
\text { Means (SD) }\end{array}$ & $p$ values & $\eta_{p}^{2}$ & $\begin{array}{l}\text { Son-in-law } \\
\text { Means (SD) }\end{array}$ & $\begin{array}{l}\text { Daughter-in-law } \\
\text { Means (SD) }\end{array}$ & $p$ values & $\eta_{p}^{2}$ \\
\hline Good father/mother & n.s. & n.s. & n.s. & n.s. & $2.37(0.75)$ & $2.46(0.70)$ & .024 & 0.016 \\
\hline Loves his/her family & n.s. & n.s. & n.s. & n.s. & $2.40(0.76)$ & $2.41(0.75)$ & n.s. & n.s. \\
\hline Wants children & n.s. & n.s. & n.s. & n.s. & $2.20(0.72)$ & $2.30(0.74)$ & .004 & 0.025 \\
\hline Moral & n.s. & n.s. & n.s. & n.s. & $2.12(0.80)$ & $2.26(0.78)$ & .002 & 0.030 \\
\hline Trustful & n.s. & n.s. & n.s. & n.s. & $2.35(0.70)$ & $2.28(0.74)$ & .026 & 0.016 \\
\hline Honest & n.s. & n.s. & n.s. & n.s. & $2.34(0.75)$ & $2.40(0.71)$ & n.s. & n.s. \\
\hline Faithful & n.s. & n.s. & n.s. & n.s. & $2.41(0.74)$ & $2.40(0.72)$ & n.s. & n.s. \\
\hline Good character & n.s. & n.s. & n.s. & n.s. & $2.24(0.78)$ & $2.29(0.80)$ & n.s. & n.s. \\
\hline Healthy & n.s. & n.s. & n.s. & n.s. & $2.21(0.73)$ & $2.30(0.71)$ & .037 & 0.014 \\
\hline Sincere & n.s. & n.s. & n.s. & n.s. & $2.24(0.70)$ & $2.25(0.68)$ & n.s. & n.s. \\
\hline Emotionally stable & n.s. & n.s. & n.s. & n.s. & $2.36(0.71)$ & $2.32(0.70)$ & n.s. & n.s. \\
\hline Stable & n.s. & n.s. & n.s. & n.s. & $2.19(0.75)$ & $2.24(0.77)$ & n.s. & n.s. \\
\hline Family-oriented & n.s. & n.s. & n.s. & n.s. & $2.14(0.72)$ & $2.23(0.72)$ & .031 & 0.015 \\
\hline Good economic prospects & $1.93(0.48)$ & $1.91(0.49)$ & n.s. & n.s. & $1.96(0.49)$ & $1.85(0.47)$ & $<.001$ & 0.092 \\
\hline Financially independent & n.s. & n.s. & n.s. & n.s. & $1.84(0.75)$ & $1.74(0.74)$ & .039 & 0.013 \\
\hline Good provider & n.s. & n.s. & n.s. & n.s. & $1.86(0.78)$ & $1.64(0.76)$ & $<.001$ & 0.055 \\
\hline Good economic prospects & n.s. & n.s. & n.s. & n.s. & $1.86(0.71)$ & $1.70(0.68)$ & .001 & 0.034 \\
\hline Educated & n.s. & n.s. & n.s. & n.s. & $1.90(0.68)$ & $1.89(0.70)$ & n.s. & n.s. \\
\hline Industrious & n.s. & n.s. & n.s. & n.s. & $2.26(0.73)$ & $2.15(0.70)$ & .011 & 0.019 \\
\hline Dynamic & n.s. & n.s. & n.s. & n.s. & $1.98(0.71)$ & $1.87(0.72)$ & .011 & 0.020 \\
\hline Intelligent & n.s. & n.s. & n.s. & n.s. & $1.99(0.69)$ & $1.96(0.68)$ & n.s. & n.s. \\
\hline Exciting personality & $1.78(0.50)$ & $1.80(0.47)$ & n.s. & n.s. & $1.78(0.45)$ & $1.81(0.46)$ & n.s. & n.s. \\
\hline
\end{tabular}

law, but the "trustful" component is valued significantly more in a son-in-law than in a daughter-in-law.

The "good economic prospects" is valued more in a son-inlaw than in a daughter-in-law, with almost all its constituent traits to be significantly different in this direction. Moreover, the "reliable and tolerant" appears to be preferred more in a son-in-law than in a daughter-in-law, but the means practically overlap, mainly because its constituent traits are preferred

Table 2 Sex differences in traits which do not load in the 10 in-law preference domains

\begin{tabular}{|c|c|c|c|c|c|c|c|c|}
\hline Traits & $\begin{array}{l}\text { Mother } \\
\text { Means (SD) }\end{array}$ & $\begin{array}{l}\text { Father } \\
\text { Means (SD) }\end{array}$ & $p$ values & $d$ & $\begin{array}{l}\text { Son-in-law } \\
\text { Means (SD) }\end{array}$ & $\begin{array}{l}\text { Daughter-in-law } \\
\text { Means (SD) }\end{array}$ & $p$ values & $d$ \\
\hline Mature & $2.17(0.70)$ & $2.06(0.78)$ & .013 & 0.15 & $2.09(0.79)$ & $2.14(0.75)$ & n.s. & n.s. \\
\hline Confident & $1.96(0.76)$ & $1.99(0.72)$ & n.s. & n.s. & $1.97(0.72)$ & $1.98(0.77)$ & n.s. & n.s. \\
\hline Positive & $1.87(0.76)$ & $1.88(0.72)$ & n.s. & n.s. & $1.85(0.73)$ & $1.89(0.72)$ & n.s. & n.s. \\
\hline Sweet & $1.77(0.73)$ & $1.73(0.71)$ & n.s. & n.s. & $1.67(0.70)$ & $1.82(0.70)$ & $<.001$ & 0.21 \\
\hline Clean & $2.17(0.73)$ & $2.11(0.78)$ & n.s. & n.s. & $2.10(0.75)$ & $2.18(0.73)$ & n.s. & n.s. \\
\hline Magnanimous & $1.99(0.76)$ & $1.95(0.72)$ & n.s. & n.s. & $2.00(0.67)$ & $1.94(0.78)$ & n.s. & n.s. \\
\hline Affectionate & $2.03(0.70)$ & $1.96(0.75)$ & n.s. & n.s. & $2.00(0.69)$ & $1.99(0.77)$ & n.s. & n.s. \\
\hline $\begin{array}{l}\text { Few sexual experiences } \\
\text { before marriage }\end{array}$ & $1.44(0.81)$ & $1.47(0.81)$ & n.s. & n.s. & $1.30(0.75)$ & $1.62(0.92)$ & $<.001$ & 0.29 \\
\hline Energetic & $1.84(0.72)$ & $1.86(0.71)$ & n.s. & n.s. & $1.75(0.73)$ & $1.95(0.67)$ & $<.001$ & 0.18 \\
\hline Conscientious & $2.06(0.72)$ & $2.02(0.73)$ & n.s. & n.s. & $1.98(0.92)$ & $2.11(0.73)$ & .003 & 0.19 \\
\hline Lively & $1.92(0.69)$ & $1.93(0.68)$ & n.s. & n.s. & $1.91(0.64)$ & $1.94(1.94)$ & n.s. & n.s. \\
\hline Smiling & $2.00(0.67)$ & $1.87(0.73)$ & $<.001$ & 0.19 & $1.86(0.64)$ & $1.99(0.71)$ & .002 & 0.19 \\
\hline Optimist & $2.03(0.80)$ & $2.01(0.74)$ & n.s. & n.s. & $2.01(0.79)$ & $2.03(0.75)$ & n.s. & n.s. \\
\hline
\end{tabular}


similarly in a daughter-in-law and in a son-in-law, with the exceptions of "determined" and "generous," which are valued more in a son-in-law than in a daughter-in-law.

From Table 2 we can see that "sweet," "few sexual experiences before marriage," "energetic," "conscientious," and "smiling" are traits which are preferred more in a daughterin-law than in a son-in-law.

\section{Mothers vs. Fathers}

As we can see from Table 1, it appears that fathers value "good looks" more than mothers. An examination of the constituent traits indicates that fathers consider "good looking" and "tall" more important, while mothers consider "beautiful eyes" more important. Fathers appear to value "spontaneous and selfless" more than mothers, with the means being very close. Analysis of the constituent components indicates that "imaginative" and "extrovert" are valued more by fathers, while "openminded" is valued more by mothers.

The "well-off family background" is valued more by fathers than by mothers, with the differences being predominantly over "from a wealthy family" and "wealthy" sub-traits. The "similar religious and ethnic background" is valued more by mothers than by fathers. However, analysis of the constituent traits indicates that mothers value "same nationality" more, while fathers value "similar political beliefs" more. Note that if Bonferroni correction is applied, the sex differences would be significant only for the well-off family background and the similar religious and ethnic background.

No significant sex difference was found for the "kind, understanding, and cooperative"; note, however, that the "kind" constituent trait was preferred significantly more by mothers than by fathers $\left[F(1,325)=2.49, p=.027, \eta_{p}{ }^{2}=0.015\right]$. Finally, from Table 2 we can see that mature and smiling are preferred more by mothers than by fathers.

\section{Interactions}

The analysis produced several significant interaction effects. In particular, for the analysis based on the 10 domains, a significant interaction between the sex of the parent and the sex of the in-law was found for the similar religious and ethnic background domain $\left[F(5,324)=3.16, p=.008, \eta_{p}{ }^{2}=0.046\right]$. The interaction is significant only for the "good family background" sub-component $[F(1,328)=9.21, p=.003$, $\left.\eta_{p}{ }^{2}=0.027\right]$, where for a prospective daughter-in-law, fathers place more emphasis than mothers, while when we move to the prospective son-in-law, the difference reverses, with mothers placing more emphasis than fathers. In addition, there was a significant interaction for the kind, understanding, and cooperative $\left[F(7,319)=2.06, p=.048, \eta_{p}{ }^{2}=0.043\right]$, where parents' scores are similar for a prospective daughter-in-law, but when we move to a prospective son-in-law, mothers give higher scores than fathers.

For the traits which do not load in the 10 domains, a significant interaction between the sex of the parent and the sex of the in-law was found for the energetic $[F(1,326)=8$, $\left.p=.005, \eta_{p}{ }^{2}=0.024\right]$, the conscientious $[F(1,328)=8$, $\left.p=.002, \eta_{p}{ }^{2}=0.029\right]$, the few sexual experiences $[F(1$, $\left.328)=6.71, p=.005, \eta_{p}{ }^{2}=0.023\right]$, and the smiling $[F(1$, $\left.326)=7.54, p=.006, \eta_{p}{ }^{2}=0.023\right]$. Here, for a prospective daughter-in-law, fathers place more emphasis than mothers, while when we move to the prospective son-in-law, the difference reverses with mothers placing more emphasis than fathers. Note, however, that as indicated by the effect size, the differences are small.

\section{Further Analysis}

The original study asked participants to indicate their wealth level and religiosity using seven-point Likert scales (i.e., 1, very poor; 7, very wealthy; 1 , not religious at all; 7, very religious). Accordingly, the current dataset allows us to examine whether fathers and mothers look for similarity in a prospective mate with respect to wealth and religion. With respect to the wealth level, we performed a multiple regression where participants' answer to question about their level of wealth entered as the independent variable, and participants' preference for a wealthy in-law (a subcomponent of well-off family background) entered as the dependent variable. Moreover, in order to control for any confounding effects, we have also entered age as an independent variable. Separate regressions were performed for mothers and fathers.

For mothers and sons-in-law, the wealth status came significant with a positive coefficient $(p=.002, b=0.164)$. This was also the case for mothers and daughters-in-law $(p<.001$, $b=0.243$ ). For fathers and sons-in-law, the wealth status came significant with a positive coefficient $(p<.001, b=0.327)$, as it was for fathers and daughters-in-law $(p<.001, b=0.328)$. These results indicate that the wealthier the parents perceive themselves to be, the wealthier they want their sons- and daughters-in-law to be. This effect appears to be more pronounced for fathers, as indicated by the larger regression coefficients.

With respect to religiosity, for mothers and sons-in-law, the religious came significant with a positive coefficient $(p=.002$, $b=0.082)$. This was also the case for mothers and daughtersin-law $(p<.001, b=0.166)$. For fathers and sons-in-law, the religious came significant with a positive coefficient $(p<.001$, $b=0.188)$, as it was for fathers and daughters-in-law $(p<.001$, $b=0.191)$. As above, the observed effect appears to be more pronounced for fathers, as indicated by the larger regression coefficients. 


\section{Discussion}

The results of this study indicate that for several domains, parents' preferences are contingent upon the sex of the inlaw. On the other hand, the preferences of mothers and fathers largely overlap. This is not the case in all domains however, as fathers appear to value more than mothers the well-off family background of their prospective in-laws, while for the similar religious and ethnic background, the same nationality trait is valued more by mothers and the similar political beliefs trait more by fathers.

The difference over the well-off family background is consistent with the hypothesis that fathers would be more willing than mothers to use the marriage of their children in order to benefit themselves. For instance, in a context where mate choice is regulated, this preference would motivate fathers to make compromises on other traits, such as good character, in order to ally with a wealthy family; these compromises may not be to the best interest of their children and female partners.

Note that Apostolou (2014a) did not find this difference, but found instead that several traits were considered more important by mothers. The differences in the findings between the two studies may reflect differences in design. We consider that the present study is more ecologically valid, as it compared the preferences of fathers and mothers who had children together, while the Apostolou (2014a) study compared the preferences of unrelated fathers and mothers. Still, future research needs to attempt to replicate these findings in different samples and within different cultural settings.

With respect to the similar religious and ethnic background traits, men tend to exhibit a stronger interest in politics than women (Geary 2009), which probably accounts for their stronger interest in political similarity between themselves and their prospective in-laws. That is to say, fathers consider politics important, so the lack of similarity in this domain is likely to lead to conflict with their prospective in-laws. On the other hand, for women, social life and similar culture are likely to be more important (Geary 2009), so different nationality in an in-law is likely to indicate differences in these areas. This can be one of the reasons why mothers place more emphasis than fathers on same nationality. The observed difference may also relate to the parasite-stress model. Out-groups may often harbor novel parasites that cannot be defended against by individuals or their immunologically similar in-group members (Fincher and Thornhill 2012). Women may be more sensitive in avoiding parasites than men as means to protect their children, and, thus, they may experience a stronger dislike of out-group members.

Also, there is some evidence that mothers ascribe more value to kindness in an in-law, especially in a prospective son-in-law. Nevertheless, this sex difference was not found for the domain of kind, understanding, and cooperative, while the interaction is close to the significance level. Accordingly, future research needs to attempt to investigate this sex difference further in different samples and within different cultural settings.

The findings of this study have implications for understanding intrafamily dynamics. To begin with, when advising their children about optimal mates, parents are expected to stress more the good financial prospects in a male than a female mate, while they are expected to stress good looks and housekeeping abilities more in a female than in a male mate. They are also expected to be more dissatisfied/satisfied if their daughters than their sons date or marry someone with poor/good financial prospects, and they are expected to be more dissatisfied/satisfied if their sons than their daughters date or marry someone of poor/good housekeeping capacity or looks. Fathers are expected to be more dissatisfied than mothers if their children date individuals from families of different political beliefs who are not well-off, while mothers are expected to be more dissatisfied than fathers if their children date individuals of different nationalities. However, parents are expected to be generally in agreement on how they feel about their children's mate choices.

Evidence from the anthropological and historical records suggests that parental control over mating has been present during human evolutionary time, which means that parental choice had been a significant sexual selection force driving human evolution (Apostolou 2014c). To which direction parental choice drives human evolution depends on in-law preferences. Assuming that the contingencies found here are the products of selection pressures, then similar contingencies should have been present during human evolutionary time. Thus, we expect that in-law preferences would have shaped differently the adaptations involved in addressing parental choice. For instance, men would be under stronger selection pressure than women to signal their resource provision capacities to their prospective parents-in-law. In turn, this is likely to give rise to adaptations enabling men to reliably signal resources provision capacity, such as collecting difficult to find objects (Apostolou 2014c); these adaptations would be less pronounced in women.

The findings of this study further suggest that individuals would tend to signal their wealth status predominantly to prospective fathers-in-law than mothers-in-law. Still, given the considerable convergence in in-law preferences between mothers and fathers, we do not expect considerable differentiation in the adaptations which address parental choice. Furthermore, it is important to stress that the finding that fathers and mothers have largely overlapping preferences does not indicate how costly for children compromises in desirable traits each party is willing to make. In particular, the observed convergence in in-law preferences suggests that the bundle of traits that fathers prefer would be similar to the bundle of traits that mothers prefer in a prospective in-law. The observed divergence over well-off family background suggests that the 
father's bundle would have more of well-off family background than the mother's bundle. This finding should not be interpreted, however, as fathers being more willing than mothers to make compromises that are costly for their children in order to get more of well-off family background. To examine whether this is the case, a different research design is required (e.g., Apostolou 2015a).

This research is not without limitations. To begin with, it is based on self-report evidence, which raises questions about honesty. For instance, individuals may not be willing to admit that they want different things in a prospective in-law for their daughters than for their sons. If this is the case, the contingencies in preference with respect to the sex of a prospective inlaw may be more pronounced than what we find here. In addition, there is no guarantee that parents will act on their preferences when they find themselves in a situation where they can exercise influence on their children's mate choices. Last but not least, preferences are not rigid but adaptable to local conditions (Buss et al. 2001). This suggests that there would be variation in the observed preferences across different cultural settings. The present study is based on data collected in a single culture, and the differences found here may not be the same within other cultural contexts. We expect cross-cultural variation to be in the magnitude and not on the presence and direction of the differences; future studies need to examine whether this is actually the case.

Last but not least, the present research has examined only two factors which are likely to affect in-law preferences, namely the sex of the in-law and the sex of the parent. Nevertheless, there are likely to be many other factors, including personality, social status, financial status, religiosity, and personal values, which may affect in-law preferences. For instance, parents who score high in agreeableness may ascribe more value to their prospective in-laws being kind and understanding than parents who score low in this dimension. Future research needs to promote further our understanding of in-law preferences by identifying additional factors that affect them.

\section{Are In-Law Preferences Actually Mate Preferences?}

It can be argued that in ancestral human societies there had not been substantial selection pressures for distinct in-law preferences to evolve; therefore, what we measure here as in-law preferences are actually "masked" mate preferences. This can possibly explain the observed similarity in contingencies; for instance, beauty is valued more in wife than in a spouse and it is valued more in a daughter-in-law than in a son-in-law. This argument is not valid for several reasons.

To begin with, as discussed in "Introduction," evidence from the anthropological and historical records along with phylogenetic studies indicates that in ancestral human societies mate choice was regulated, with parents choosing spouses for their children and not the children for themselves
(Apostolou 2014c; Walker et al. 2011). Therefore, during human evolutionary time, parents faced recurrently the problem of choosing fitness-increasing daughters- and sons-in-law, which translates into considerable selection pressures for inlaw preferences to evolve.

Moreover, if in-law preferences were simply masked mate preferences then the two would be identical in strength, which is not the case. In particular, one line of research tested the hypothesis that people have distinct in-law and mate preferences by asking individuals who had children to rate a set of traits in a prospective spouse for themselves and in a prospective spouse for their daughters and sons (Apostolou 2008; Apostolou et al. 2014). If in-law preferences were masked mate preferences then, there would not be any differences between the two ratings; yet significant differences were found, with participants changing their preferences on the basis of whether they acted as in-laws or mate-seekers. Even more importantly, the observed differences were consistent with what evolutionary reasoning predicted that in-law preferences would differ from mate preferences, namely good looks were preferred more in a spouse than in an in-law, while good family background was preferred more in an in-law than in a spouse.

In the same line of reasoning, if in-law and mate preferences were identical, the sex differences in preferences between mothers and fathers would also mirror the difference in preference between male and female mate-seekers. More specifically, research on mate preferences has found that traits such as good economic prospects and being well-off are preferred more by women in a male partner, while traits such as beauty and good housekeeping abilities are preferred more by men in a female partner (Buss 2003). If in-law and mate preference were identical, then such differences would emerge when we compare the preferences of mothers with the preferences of fathers. Yet these differences were not found, while with respect to wealth, the difference was to the opposite direction. Fathers ascribed more importance to it than mothers.

Last but not least, if in-law and mate-preferences were identical, then the two would have the same structure; i.e., factor analysis of in-law and mate-preferences would produce identical or very similar factor structures. Research that employed factor analysis on desirable traits in a mating candidate found that in-law preferences have a different structure than mate preferences (Apostolou 2014c, 2015b). In sum, different lines of evidence converge to the conclusion that in-law preferences are distinct from mate preferences. In-law preferences are adaptations which have evolved to enable parents to choose fitness-increasing in-laws, while mate preferences are adaptations which have evolved to enable individuals to choose fitness-increasing mates.

Overall, parents exercise considerable influence on their children's mate choices. Understanding this influence requires a better understanding of in-law preferences. The present 
paper has contributed to this endeavor by finding that fathers and mothers who have children together value several traits differently in prospective in-laws depending on their sex. Future research needs to attempt to replicate these findings in different cultural contexts.

\section{References}

Apostolou, M. (2007). Elements of parental choice: the evolution of parental preferences in relation to in-law selection. Evolutionary Psychology, 5, 70-83.

Apostolou, M. (2008). Parent-offspring conflict over mating: the case of beauty. Evolutionary Psychology, 6, 303-315.

Apostolou, M. (2010a). Parental choice: what parents want in a son-inlaw and a daughter-in-law across 67 pre-industrial societies. British Journal of Psychology, 101, 695-704.

Apostolou, M. (2010b). Sexual selection under parental choice in agropastoral societies. Evolution and Human Behavior, 31, 39-47.

Apostolou, M. (2011). Parent-offspring conflict over mating: testing the tradeoffs hypothesis. Evolutionary Psychology, 9, 470-495.

Apostolou, M. (2014a). Parental choice: exploring in-law preferences and their contingencies in the Greek-Cypriot culture. Evolutionary Psychology, 12, 54-72.

Apostolou, M. (2014b). Sexual selection under parental choice: a revision to the model. Theory in Biosciences, 133, 111-115.

Apostolou, M. (2014c). Sexual selection under parental choice: the evolution of human mating behaviour. Hove: Psychology Press.

Apostolou, M. (2015a). Inter-parental disagreement over in-law choice. Personal Relationships, 22, 285-298.

Apostolou, M. (2015b). Parent-offspring conflict over mating: domains of agreement and disagreement. Evolutionary Psychology, 13 Retrieved from http://evp.sagepub.com/content/13/3/ 1474704915604561.full.pdf + html

Apostolou, M., \& Papageorgi, I. (2014). In-law choice and the search for similarity. Personality and Individual Differences, 66, 106-111.

Apostolou, M., Philippou, D., Andronikou, Z., Argyridou, K., Kasapi, K., Kourouklari, I., \& Antoniou, A. (2014). Divergence between in-law and mate preferences: evolved predispositions or socialization and experience effects? Personality and Individual Differences, 70, 5761.
Broude, G. J., \& Green, S. J. (1983). Cross-cultural codes on husbandwife relationships. Ethnology, 22, 263-280.

Buss, D. M. (2003). The evolution of desire: strategies of human mating (2nd ed.). New York: Basic Books.

Buss, D. M., Shackelford, T. K., Kirkpatrick, L. A., \& Larsen, R. J. (2001). A half century of mate preferences: the cultural evolution of values. Journal of Marriage and Families, 63, 492-503.

Buunk, A. P., Park, J. H., \& Dubbs, S. L. (2008). Parent-offspring conflict in mate preferences. Review of General Psychology, 12, 47-62.

Dubbs, S. L., \& Buunk, A. P. (2010). Parents just don't understand: parent-offspring conflict over mate choice. Evolutionary Psychology, 8, 586-598.

Emlen, S. T., \& Oring, L. W. (1977). Ecology, sexual selection, and the evolution of mating systems. Science, 197, 215-223.

Fincher, C. L., \& Thornhill, R. (2012). Parasite-stress promotes in-group assortative sociality: the cases of strong family ties and heightened religiosity. Behavioral and Brain Sciences, 35, 61-119.

Geary, D. C. (2009). Male, female: the evolution of human sex differences (2nd ed.). Washington: American Psychological Association.

Goode, W. J. (1982). The family (2nd ed.). Upper Saddle River: Prentice Hall.

Lee, R. B., \& Devore, I. (1968). Man the hunter. New York: Aldine.

Li, N. P., Bailey, J. M., Kenrick, D. T., \& Linsenmeier, J. A. W. (2002). The necessities and luxuries of mate preferences: testing the tradeoffs. Journal of Personality and Social Psychology, 82, 947955.

Perilloux, C., Fleischman, D. S., \& Buss, D. M. (2011). Meet the parents: parent-offspring convergence and divergence in mate preferences. Personality and Individual Differences, 50, 253-258.

Puts, D. A. (2010). Beauty and the beast: mechanisms of sexual selection in humans. Evolution and Human Behavior, 31, 157-175.

Stephens, W. N. (1963). The family in cross-cultural perspective. New York: Holt, Rinehart \& Winston.

Trivers, R. L. (1972). Parental investment and sexual selection. In B. Campbell (Ed.), Sexual selection and the descent of man: 18711971 (pp. 136-179). Chicago: Aldine.

Trivers, R. (1974). Parent offspring conflict. American Zoologist, 24, 249-264.

Walker, R. S., Hill, K. R., Flinn, M. V., \& Ellsworth, R. M. (2011). Evolutionary history of hunter-gatherer marriage practices. PLoS ONE, 6, e19066.

Whyte, M. K. (1978). The status of women in preindustrial societies. Princeton: Princeton University Press. 